\title{
Role of agnikarma in the management of chronic plantar fasciitis
}

\author{
Case Study
}

\section{Anantkumar V. Shekokar ${ }^{1^{*}}$, Kanchan M. Borkar²}

1. Reader \& H. O. D, 2. Lecturer, Dept of Shalya Tantra

S. V. N. H. T's Ayurved Mahavidyalaya, Rahuri factory. Maharashtra

\begin{abstract}
Chronic plantar Fasciitis is a common Condition in painful heel. Heel pain is observed in number of conditions like sever's disease, Calcaneal knob, Bursitis, bony spur, Pagets, Orteomyelitis, acute plantar fasciitis and chronic plantar fascitis. Management of the above condition is done by medicine, para surgical procedure and surgical procedures as per requirement. But these treatments modalities are lengthy having complications and are not suitable for common people belonging to developed countries.

As the reference of Acharya Sushruta suggests the disease chronic plantar fasciitis can be correlated with Vatakantaka. Vatakantaka is Snaya Asthi Sandhi Aashrita, so the patient should be kept under Agnikarma therapy upto a satisfactory level of relief from pain. It may be for long duration and hence in this study a case of chronic plantar fasciitis was treated by Agnikarma for a period of 45 days. In this period 6 sittings was administered at the interval of 7 days giving a complete relief from pain. After completion of Agnikarma, the patient was followed up and observed for recurrence for 3 months.
\end{abstract}

Keywords: Agni karma, Plantar fasciitis, Painful heel

\section{Introduction}

Painful heel is common complaint which is often received from an individual of any age. There are various conditions causing heel pain in different age groups. In children sever's disease is observed mostly in boys which is type of 'traction osteochondritis'. In adolescent girls calcaneal knob is uncommonly observed. In adult women bursitis is common and acute plantar fasciitis may be found with gonorrhea (1).

In patients belonging to middleaged groups, bony spur and chronic plantar fasciitis is commonly observed (2). The

\footnotetext{
*Corresponding Author:

\section{Anantkumar V Shekokar}

Reader \& HOD Dept of Shalya Tantra

S. V. N. H. T'S Ayurved Mahavidyalaya, Rahuri Factory, Maharashtra

Phone No: +91-9860376534

E-mail: dranantkumarshekokar@gmail.com
}

exact pathology of chronic plantar fasciitis is not known but it is more often seen in men between 40 to 60 years of age who are more prone for ill fitting footwear (3). There is an early morning stiffness, restricted movement, pain and tenderness below the calcaneus (4). To get relief from pain, initially a soft pad may be used just below the tender area. If this does not help, injection of Hydrocortisone should be made at the most tender spot. If this fails then lastly division of the plantar fascia is indicated (5). But all these measures have side effects, complications and are time consuming. Moreover they do not give permanent cure for the disease. It is therefore, very uneconomical for a common man to afford all these costly measures.

According to Acharya Sushruta chronic plantar fasciitis can be correlated with Vatakantaka which is caused by vitiated Vata Dosha due to constant 
standing and walking on uneven surface resulting into pain in foot (Heel) (6). Sushruta also mentioned that the disease Vatakantaka is Snayu Asthi Sandhi Ashrit and such diseases should be treated with oleation , poultice, Agnikarma, Bandaging and massage upto a considerable relief from pain (7). Hence a case study of Agnikarma in management of chronic plantar fasciitis was selected. Here we shall study a case of a 45 year aged patient working as an agriculture labor who visited to OPD of Shalyatantra Department of Ayurved Mahavidyalaya , Rahuri on $10^{\text {th }}$ May 2013 with complaints of painful heel, tenderness, restricted movements and early morning stiffness at the right heel. There was history of previous treatment for chronic plantar fasciitis under private orthopedic surgeon since the last four months. The history suggested that he had received analgesic, anti inflammatory, steroid and two sittings of hydrocortisone injection but without any significant and satisfactory relief,henceafter. Routine Blood investigation and $\mathrm{x}$-ray examination of heel were done and all investigations were found normal. After careful assessment and examinations patient was diagnosed with nonspecific chronic plantar fasciitis and it was decided that this be treated with Agnikarma Chikitsa only at an interval of seven days upto complete relief from pain. Patient got relief from pain after completion of first sitting. After the completion of $3^{\text {rd }}$ sitting patient got relief from early morning stiffness whereas tenderness and restricted movement were relieved after the completion of $6^{\text {th }}$ sitting without any adverse effects being observed throughout the entire sittings. To observe any recurrence of symptoms patient was followed upto 3 month but recurrence of symptoms were not observed. Patient was fully satisfied with Agnikarma Chikitsa as compared to previously treated with modern

\section{Procedure of Agnikarma}

After taking inform written consent the affected part was cleaned with Triphala Kashaya. It was then wiped with dry sterilized cotton gauze (8). Red hot Panchdhatu Shalaka was used for making Bindu Dahan Vishesh and 18-20 Samyak Dagdh Vrana were made by Panchadhatu Shalaka. It is to be noted that a proper space between two Samyak Dagdh Vrana should be kept after making Samyak Dagdha Vrana. Also, the Kumari Swarasa should be applied on that to get relief from burning sensation. After wiping of Kumari Swarasa dusting of Yashtimadhu churna should be applied (9).

Above procedure was repeated 6 times at the interval of 7 days and patient was advised to apply the paste of Haridra powder mixed with coconut oil at bed time upto nornal appearance of skin.

\section{Discussion}

Chronic planer fasciitis can develop due to use of walking on uneven roads with ill fitting footwear which causes silent and repeated injury resulting into inflammation of plantar fascia which results in the painful heel, tenderness, early morning stiffness and restricted movements of heel. As per Ayurvedic concept, this condition may develop as the vitiation of Vata with Anubandha of Kapha Dosha. Vata and Kapha Dosha have been considered as the important factors for causation of Shotha (inflammation) and Shoola (pain) in the heel.

Agnikarma Chikitsa introduces heat in the affected area. This heat is Ushna, Tikshna, Laghu, Sukshma, Vyavayi and Vikashi in Guna which is helpful to break the Kaphanubandha thus reducing shoth and ultimatly Vata Dosha gets neutralised so that Shool (pain and tenderness) is relieved. To manage such a condition Agnikarma Chikitsa is creditable treatment. 


\section{Conclusion}

1. Agnikarma therapy is OPD procedure.

2. Agnikarma therapy is mostly helpful in management of local pathological diseases.

3. During procedure of Agnikarma one should not exert excessive pressure unless it will produces Atidagdha vrana.

4. Scar of Dagdha Vran produced by Agnikarma disappeared within 3 weeks.

5. Number of sitting of Agnikarma depends upon chronicity and severity of the disease.

Thus from the above study it can be concluded that Agnikarma procedure proves to be one of the easiest way to reduce the plantar fascities.

\section{Acknowledgements}

- The Author expresses his sincere gratitude to Prof. P. R. Adhav. (Dean,Ayurved

Mahavidlaya,Rahuri,Maharashtra) .

- Our sincere thank you to Pandurang J. Jadhav our beloved student.

\section{References}

1. Das S.; A concise text book of surgery ; S. Das publication, Calcutta, $4^{\text {th }}$ edition, 1999, pg. no. 496.

2. Clinical Orthopaedic Examination,Ronald McRae,Churchill
Livingstone Edinburgh London New York Philadelphia St Louis Sydney Toronto 1998,Fourth Edition, Vol. 1,Page no. 262.

3. John Ebnezar, Text Book Of Orthopaedics, Jaypee Brothers Medical Publishers (P) LTD New Delhi,Second Edition 2003,Page no. 225

4. J. Maheshwari, Essential Orthopaedics, Mehta publishers New Delhi 2002, Third Edition page no. 259.

5. Das S.;A concise text book of surgery ; S. Das publication, Calcutta, $4^{\text {th }}$ edition, 1999, pg. no. 497.

6. Yadavji Trikamji Acharya; Sushrut Samhita of Sushruta with commentary of Dalhanacharya, chaukhamba surbharati prakashana, Varanasi,2003, Nidana Sthan,Adhyaya no. 01 , Vatavyadhi Nidana,Sutra no. 79 pg. no. 269.

7. Anantram Sharma, Sushruta Samhita Part-2 , Chokhamba Surbharati Prakashan, Varanasi, $1^{\text {st }}$ Edition, 2001,Chikitsa Sthana,Adhyaya no. 04 , Vatavyadi Chikitsa,Sutra no. 08, Page no. 205.

8. Devendranatha pande, Anushtra karma parasurgical therapy at a glance, Vol. 1, Edition $1^{\text {st }}$, . Chaukhambha Publication, 2009, Varansi,Page no. 75.

9. Gupta P. D., Agnikarma Technological Innovation (Treatment by therapeutic Burning), Vol. 1, Edition $1^{\text {st }}$, . Prabha Publication, 1992,Nagpur,Page no. 32. 


\section{PHOTOGRAPHS}

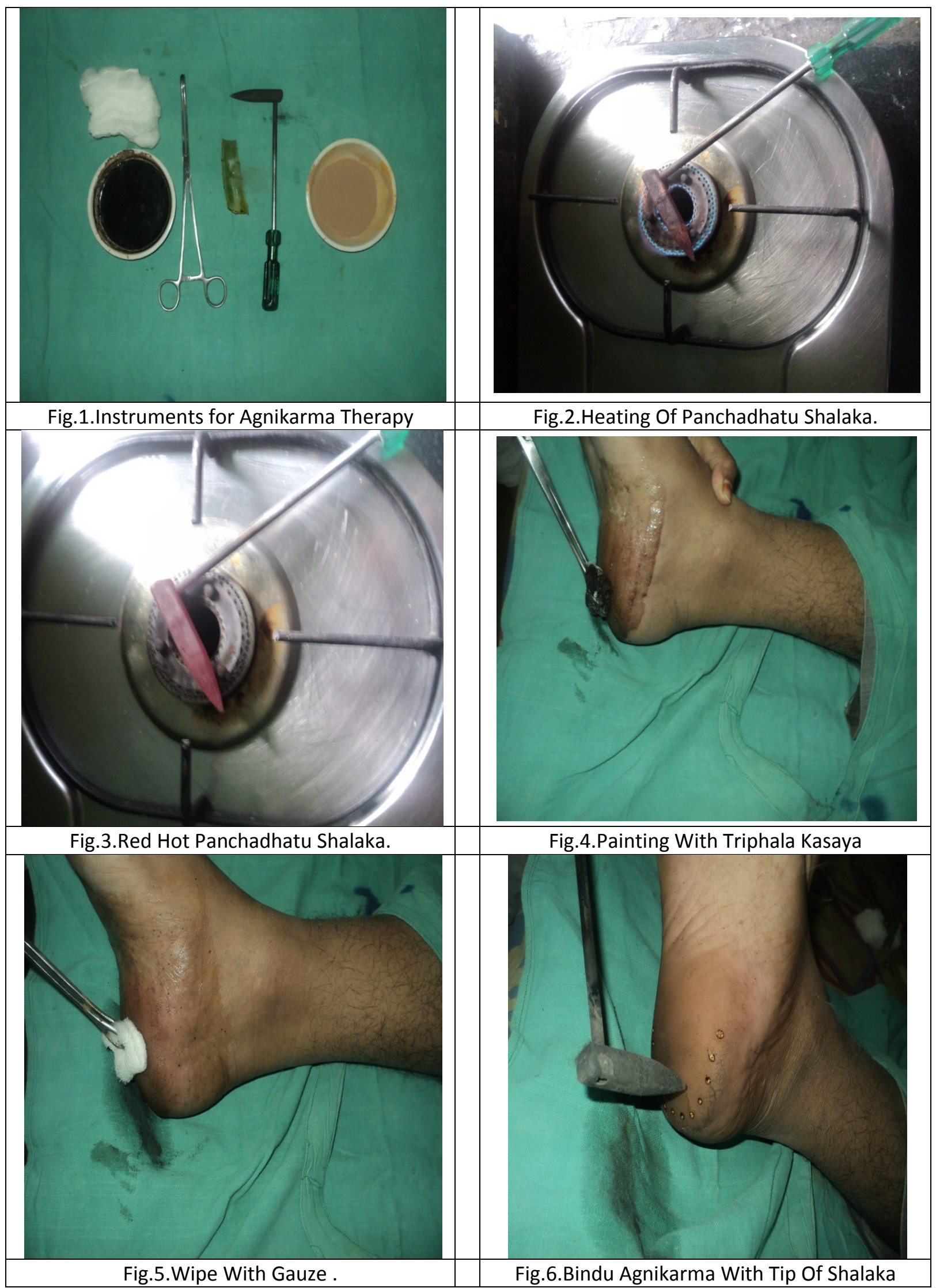




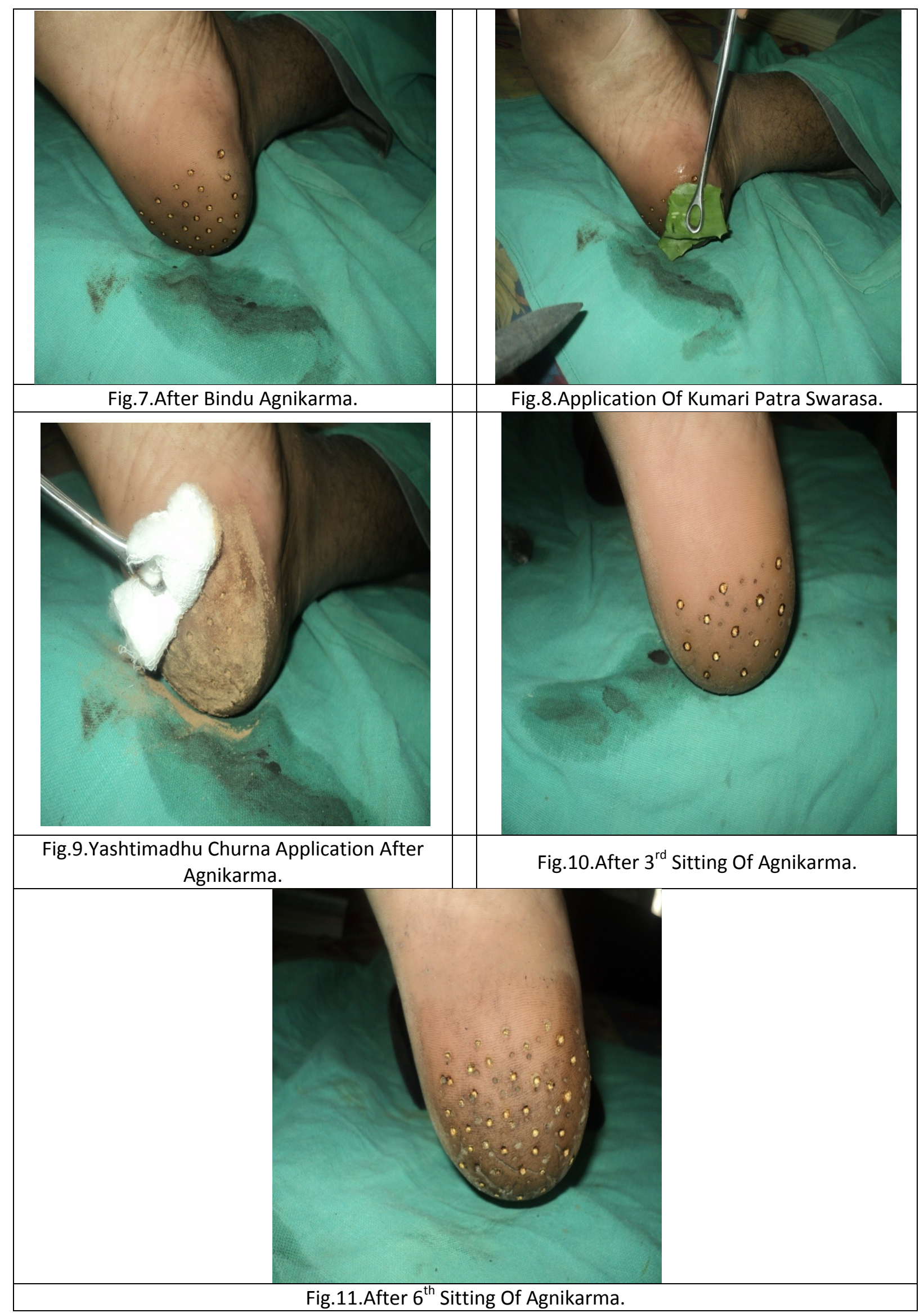

